\title{
Development of polymorphic expressed sequence tag-single sequence repeat markers in the common Chinese cuttlefish, Sepiella maindroni
}

\author{
R.H. Li, S.K. Lu, C.L. Zhang, W.W. Song, C.K. Mu and C.L. Wang \\ School of Marine Science, Ningbo University, Ningbo, China \\ Corresponding author: C.L. Wang \\ E-mail: wangchunlin@nbu.edu.cn
}

Genet. Mol. Res. 13 (3): 5503-5506 (2014)

Received June 7, 2013

Accepted September 18, 2013

Published July 25, 2014

DOI http://dx.doi.org/10.4238/2014.July.25.3

\begin{abstract}
The common Chinese cuttlefish (Sepiella maindroni) is one of the popular edible cephalopod consumed across Asia. To facilitate the population genetic investigation of this species, we developed fourteen polymorphic microsatellite makers from expressed sequence tags of $S$. maindroni. The number of alleles at each locus ranged from 6 to 10 with an average of 7.9 alleles per locus. The ranges of observed and expected heterozygosity were from 0.615 to 0.962 and 0.685 to 0.888 , respectively. Four loci were found deviated significantly from Hardy-Weinberg equilibrium. The polymorphism information content ranged from 0.638 to 0.833 . These polymorphic microsatellite loci will be helpful for the population genetic, genetic linkage map, and other genetic studies of $S$. maindroni.
\end{abstract}

Key words: Expressed sequence taq; Microsatellite marker; Common Chinese cuttlefish; Sepiella maindroni 


\section{INTRODUCTION}

The common Chinese cuttlefish Sepiella maindroni is distributed widely along the coast of Eastern Russia, Japan, North Korea, China, Malaysia, and Philippine Islands (Zheng et al., 2001; Wu et al., 2006). As a popular edible cuttlefish, it is one of the most high-productive economic cephalopod harvested from the sea. Basic research, including physiology, reproductive biology, and embryology, of this species has been performed (Jiang et al., 2011; Wu et al., 2012). Further, the investigation of the medicinal value of the ink extracts of $S$. maindroni is in progress (Liu et al., 2008). However, only limited information is available regarding the genetic diversity and population structure of this species (Zheng et al., 2003), which is very important for the conservation and sustainable exploitation of $S$. maindroni resources.

Microsatellite or simple sequence repeat (SSR) markers represent one of the most powerful tools for the analysis of population structure and genetic diversity due to their genetic co-dominance, relative abundance, multi-allelic variation, and high reproducibility (Rajwant et al., 2011). To date, 10 microsatellite markers from $S$. maindroni have been reported by $\mathrm{Wu}$ et al. (2010). Additional loci will be needed to benefit the research of population genetics, genetic diversity, and genetic linkage map construction.

The SSRs derived from expressed sequence tag (EST) have many intrinsic advantages over genomic microsatellites for their higher transferability among related species, lower cost for development, and higher proportion of high-quality markers (Varshney et al., 2005). In this study, we developed 14 highly polymorphic microsatellite markers from ESTs of S. maindroni that will be useful for genetic research of this species.

\section{MATERIAL AND METHODS}

In all, 9439 EST sequences of S. maindroni were obtained, of which 899 sequences were downloaded from the GeneBank and 8540 were collected from the juvenile cDNA library constructed by our laboratory (data unpublished). Putative EST-SSR markers were screened using the SSRHUNTER 1.3 software (http://www.biosoft.net/dna/SSRHunter.htm). The criteria used in SSRHUNTER to identify microsatellites were as follows: 5 repeats for di-, tri-, and tetranucleotide repeats. Primers flanking microsatellites were designed using the PRIMER 5.0 program (http://www.premierbiosoft. com/).

Polymorphism evaluation was tested using 30 wild individuals of $S$. maindroni collected from Liuheng, Zhejiang Province, China. Genomic DNA of each specimen was extracted from the muscle tissue by using a genomic DNA extraction kit (BioTeke, Beijing, China) following manufacturer protocols. Polymerase chain reaction (PCR) was performed in $10-\mu \mathrm{L}$ volumes containing $5 \mu \mathrm{L} 2 \mathrm{x}$ Power Taq PCR Master Mix (BioTeke), $1 \mu \mathrm{M}$ each primer set, and about $100 \mathrm{ng}$ template DNA. PCR was performed on a Master-cycler gradient thermal cycler (Eppendorf) with the following program: 3 min at $94^{\circ} \mathrm{C} ; 35$ cycles of $1 \mathrm{~min}$ at $94^{\circ} \mathrm{C}$, annealing (see Table 1 for annealing temperatures) for $1 \mathrm{~min}, 72^{\circ} \mathrm{C}$ for $1 \mathrm{~min}$ per cycle; followed by 5 min at $72^{\circ} \mathrm{C}$. Amplification products were resolved on $8 \%$ denaturing polyacrylamide gel and visualized by silver staining. A 10-bp DNA ladder (Invitrogen Inc.) was used as a reference marker for allele size determination.

Allele number $\left(N_{\mathrm{A}}\right)$, polymorphism information content (PIC), expected and observed heterozygosities ( $H_{\mathrm{E}}$ and $H_{\mathrm{O}}$, respectively) were analyzed using the CERVUS 3.0 software (Kalin- 
owski et al., 2007). Tested for linkage disequilibrium (LD) and deviations from Hardy-Weinberg equilibrium (HWE) were performed using GENEPOP 4.0.10 (Raymond and Rousset, 1995). Sequential Bonferroni corrections (Rice, 1989) were applied for all multiple tests $(\mathrm{P}<0.05)$.

\begin{tabular}{|c|c|c|c|c|c|c|c|c|c|c|}
\hline Locus 1 & Repeat motif & Primer sequence $\left(5^{\prime}-3^{\prime}\right)$ & $\mathrm{T}_{\mathrm{A}}\left({ }^{\circ} \mathrm{C}\right)$ & $N_{\mathrm{A}}$ & $\begin{array}{l}\text { Expected size } \\
\text { (bp) }\end{array}$ & $H_{\mathrm{o}}$ & $H_{\mathrm{E}}$ & PIC & $P_{\text {HWE }}$ & $\begin{array}{l}\text { Accession } \\
\text { No. }\end{array}$ \\
\hline SMA6 & $(\mathrm{AAG})_{21}$ & $\begin{array}{l}\text { F: TCTGCGATTAGAGGTAGAGGG } \\
\text { R: GGTATAGACGGTGGAGGAGG }\end{array}$ & 56 & 7 & $270-291$ & 0.800 & 0.776 & 0.730 & 0.560 & KC478084 \\
\hline SMA8 & $(\mathrm{GAT})_{20}$ & $\begin{array}{l}\text { F: TGTTCATTGTGGGTTGCT } \\
\text { R: ATCGTTAAAAACAATATCATAGTCA }\end{array}$ & 53 & 7 & $310-340$ & 0.920 & 0.827 & 0.783 & 0.054 & KC478087 \\
\hline SMA10 & $(\mathrm{AAG})_{20}$ & $\begin{array}{l}\text { F: TGCCAAAGGTGGTGAGAA } \\
\text { R: TTGCAGCATCTACCAATACG }\end{array}$ & 55 & 8 & $207-237$ & 0.960 & 0.803 & 0.759 & $0.002 *$ & KC478086 \\
\hline SMA20 & $(\mathrm{TA})_{8}$ & $\begin{array}{l}\text { F: GTTAGCAGCCGGAGTGTT } \\
\text { R: AAGTCAGTCTCGCTTGGT }\end{array}$ & 52 & 6 & $270-290$ & 0.720 & 0.718 & 0.671 & 0.622 & GT618356 \\
\hline SMA21 & $(\mathrm{CTC})_{7}$ & $\begin{array}{l}\text { F: TTCTCCGCCTCATTCACC } \\
\text { R: CGATAGTAACCCGTCATTTT }\end{array}$ & 55 & 6 & $187-205$ & 0.760 & 0.788 & 0.740 & 0.646 & GT618547 \\
\hline SMA36 & $(\mathrm{AGC})_{5}$ & $\begin{array}{l}\text { F: AGTAGAGTTGCTATTAAGCAGG } \\
\text { R: GCAGAACCCAAGAAACGA }\end{array}$ & 53 & 6 & $467-494$ & 0.680 & 0.685 & 0.638 & 0.629 & GT618088 \\
\hline SMA39 & $(\mathrm{TC})_{14}$ & $\begin{array}{l}\text { F: GGGGAAGAAATCTCAGGAACA } \\
\text { R: GTAACAATGGCCGTGATGAA }\end{array}$ & 57 & 9 & $212-270$ & 0.654 & 0.857 & 0.822 & 0.004 & KC869652 \\
\hline SMA40 & $(\mathrm{AC})_{14}$ & $\begin{array}{l}\text { F: ATGTTGAAACCAAGTAGATGCA } \\
\text { R: TATTTTCTTTTGGCGGGAG }\end{array}$ & 56 & 10 & $185-220$ & 0.962 & 0.800 & 0.756 & 0.564 & KC869653 \\
\hline SMA41 & $(\mathrm{AC})_{14}$ & $\begin{array}{l}\text { F: CAGATGACCCCTTGAAATGA } \\
\text { R: CACCCAGGATGATGACTATTTT }\end{array}$ & 56 & 10 & $130-166$ & 0.880 & 0.862 & 0.828 & $0.003 *$ & KC869654 \\
\hline SMA43 & $(\mathrm{CA})_{13}$ & $\begin{array}{l}\text { F: AGTTGACGCAGGAGAAAGTGT } \\
\text { R: CAATTCCACAAGCAAACCAT }\end{array}$ & 57 & 8 & $108-138$ & 0.833 & 0.888 & 0.833 & $0.000 *$ & KC869655 \\
\hline SMA47 & $(\text { TATC })_{13}$ & $\begin{array}{l}\text { F: TTCAACCTTTATGACCGACTA } \\
\text { R: CAGGTAGGTGTACGAGCAAA }\end{array}$ & 53 & 6 & 176-204 & 0.789 & 0.797 & 0.743 & 0.030 & КС869657 \\
\hline SMA54 & $(\mathrm{TAC})_{12}$ & $\begin{array}{l}\text { F: AGGTGGGGTCCTCATCTGTT } \\
\text { R: TGTTCCTGCCTGATAAAAGCA }\end{array}$ & 58 & 9 & 173-197 & 0.850 & 0.850 & 0.808 & $0.000^{*}$ & KC869656 \\
\hline SMA55 & $(\mathrm{ACT})_{12}$ & $\begin{array}{l}\text { F: TGAAAAGAGGATGGAAGAGACT } \\
\text { R: TGTTATTACCACAGAGCAGGA }\end{array}$ & 54 & 10 & $135-168$ & 0.615 & 0.852 & 0.818 & 0.011 & KC869658 \\
\hline SMA58 & $(\mathrm{CA})_{12}$ & $\begin{array}{l}\text { F: CACACCAAATTCTAACCTTCA } \\
\text { R: GTTTCCTGTTAAATTGATATGAGT }\end{array}$ & 53 & 8 & $190-216$ & 0.800 & 0.819 & 0.775 & 0.980 & KC869659 \\
\hline
\end{tabular}

$\mathrm{T}_{\mathrm{A}}=$ annealing temperature; $N_{\mathrm{A}}=$ observed number of alleles; $H_{\mathrm{O}}=$ observed heterozygosity; $H_{\mathrm{E}}=$ expected heterozygosity; $\mathrm{PIC}=$ polymorphic information content. *Significant deviation from $\mathrm{HWE}(\mathrm{P}<0.05)$.

\section{RESULTS AND DISCUSSION}

A total of 1219 microsatellite-containing EST sequences were detected from 9439 ESTs of S. maindroni. Primers were designed for 58 microsatellites because of repetition times and flaking sequence priority. Twenty-eight of the 58 primers were successfully amplified, and 14 loci were shown to be polymorphic in S. maindroni (Table 1).

The number of alleles at each locus ranged from 6 to 10 with an average of 7.9 alleles per locus. The ranges of $H_{\mathrm{O}}$ and $H_{\mathrm{E}}$ were from 0.615 to 0.962 and 0.685 to 0.888 , respectively. The PIC ranged from 0.638 to 0.833 . Significant departure from HWE was found at 4 loci after correction for multiple tests, and no significant linkage disequilibrium was found between all these loci.

The EST-SSR markers developed in this study will facilitate the elucidation of the population structure, genetic diversity, and genetic linkage map of S. maindroni.

\section{ACKNOWLEDGMENT}

Research supported by the National Natural Science Foundation of China (\#41206114; \#41176124), Ph.D. Programs Foundation of Ministry of Education of Chi- 
na (\#20103305110003), Natural Science Foundation of Zhejiang Province (\#Z3110482; \#LQ12C19002), and K C Wong Magana Fund in Ningbo University.

\section{REFERENCES}

Jiang X, Ge C, Tong Q, Tang S, et al. (2011). The embryonic development of Sepiella maindroni. J. Ningbo Univ. 24: 1-7. Kalinowski ST, Taper ML and Marshall TC (2007). Revising how the computer program CERVUS accommodates genotyping error increases success in paternity assignment. Mol. Ecol. 16: 1099-1106.

Liu C, Li X, Li Y, Feng Y, et al. (2008). Structural characterisation and antimutagenic activity of a novel polysaccharide isolated from Sepiella maindroni ink. Food Chem. 110: 807-813.

Rajwant KK, Manoj KR, Sanjay K, Rohtas S, et al. (2011). Microsatellite markers: an overview of the recent progress in plants. Euphytica 177: 309-334.

Raymond M and Rousset F (1995). GENEPOP (version 1.2): population genetics software for exact tests and ecmenicism. J. Hered. 86: 248-249.

Rice RW (1989). Analyzing tables of statistical tests. Evolution 43: 223-225.

Varshney RK, Graner A and Sorrells ME (2005). Genic microsatellite markers in plants: features and applications. Trends Biotechnol. 23: 48-55.

Wu CW, Zhao SJ and Xu DN (2006). Biology and resource of cuttlefish Sepia andreana in Zhoushan fishing area. Oceanol. Limnol. Sin. 37: 231-237.

Wu CW, Chi CF, He GY, Lu ZM, et al. (2010). Isolation via enrichment and characterization of ten polymorphic microsatellite loci in the cuttlefish, Sepiella maindroni de Rochebruns. Acta Oceanol. Sin. 29: 121-124.

Wu CW, Zhou C, Guo BY and Zhang JS (2012). Study on changes in reproductive biology characteristics of Sepiella maindroni (rochebrune) offshore Zhejiang. Oceanol. Limnol. Sin. 43: 689-694.

Zheng XD, Natsukari Y, Wang RC, Wang ZP, et al. (2001). Biochemical genetic studies on cuttlefish Sepiella maindroni (Cephalopoda: Sepiidae)-active loci screening of isozyme. Chin. J. Oceanol. Limnol. 19: 345-349.

Zheng X, Wang R, Xiao S, Yu R, et al. (2003). Genetic diversity in populations of Sepiella maindroni using 16S rRNA gene sequence analysis. High Tech. Lett. 9: 1-5. 